\title{
Order at the Margins: The Legal Construction of Interface Conflicts over Time
}

\author{
Nico Krisch, Francesco Corradini \& Lucy Lu Reimers*
}

Global Constitutionalism 9:2 (2020), 343-363

Accepted manuscript version

Final published version at https://doi.org/10.1017/S2045381719000327

\begin{abstract}
Legal multiplicity in the global realm, and the interface conflicts that ensue from it, are widely thought to have a destabilising effect, blocking the path towards a more integrated and perhaps constitutionalised global order. While this diagnosis may appear plausible if interface conflicts are seen as snapshots and rivalrous institutions as the main actors, it is less convincing if we regard these conflicts as part of social processes of contestation that define the relations between different norms over time. It is also less plausible if actors with other orientations norm irritation or navigation - are taken into view. This article works towards a more encompassing account, both temporally and as regards actor orientations. It uses two case studies of conflicts at the interface between economic governance and human rights to probe the plausibility of its conjectures. Both cases appear as instances of prolonged norm contestation which, despite continued irresolution of the underlying conflicts as a matter of law, have resulted in a significant reorientation and (partial) consolidation around new interpretations. This suggests that interface conflicts, rather than destabilising the rule of law, may also open a pathway for change in the otherwise rigid structure of the international legal order.
\end{abstract}

\footnotetext{
* Graduate Institute of International and Development Studies, Geneva. Correspondence to: nico.krisch@graduateinstitute.ch
} 


\section{Introduction}

The global legal order is one of multiplicity, composed of a great variety of norms with origin in the varying institutional contexts of formal international law, diverse forms of transnational and informal norms as well as domestic legal orders. Where these bodies of norms overlap, the potential for 'interface conflicts' between them increases - conflicts in which actors invoke norms from different origins to justify their diverging positions (Kreuder-Sonnen and Zürn, Introduction to this Special Issue). These conflicts are widely thought to have a destabilizing effect. They are seen to enhance the potential for friction because actors lack a jointly accepted reference point for settling their disputes and are instead free to pursue diverging paths with reference to norms in their favor. The legal irresolution that results from these conflicts is seen to lead to greater unpredictability, forum-shopping and non-compliance, undermining the rule of law and blocking the path towards a more integrated, perhaps constitutionalized, global order.

Yet this common depiction of the effects of interface conflicts sits uneasily with recent empirical observations, and it rests, in two important respects, on a distorted imagery. On the one hand, it paints a static picture in which interface conflicts invite binary choices and forum-shopping on the part of individual actors. If, in contrast, we adopt a diachronic perspective, we can understand such conflicts to be part of social processes that define the relation between different norms over time. These processes can be of a frictious kind with prolonged uncertainty and tension, but they can also lead to convergence, consolidation and widespread acceptance of a new legal constellation. Secondly, the standard image tends to emphasize the competition between rivalrous norm-producing institutions, each seeking to impose itself as the central actor at the expense of the other. Yet many interface conflicts involve a variety of actors with different orientations - some navigating between competing norms, others having recourse to one norm not to rival another but instead to irritate it, to change its interpretation.

In this paper, we work towards an account of interface conflicts that incorporates this double shift in perspective, both temporally as well as with respect to actor orientations. Interface conflicts appear then less as individual instances of distributional conflict and more as a particular form of norm contestation. While sometimes causing friction and uncertainty in the short term, they may in the long term be a pathway for change in an otherwise rigid structure of international law and contribute to the construction of relations between its different norms, thus shaping the global order 'after fragmentation'.

We use two case studies to probe the plausibility of our account. The cases concern the prominent tension between global economic governance and human rights, and they are relatively 'hard' cases. Pitting two spheres of authority with dissimilar rationales and institutional structures against each other, these conflicts would be expected to generate considerable friction. Observed over time, however, the picture turns out to be far more complex. It is characterized by phases of tension as well as significant convergence even as actors maintain diverging views on the relationship between competing norms. Despite this irresolution, these interface conflicts have contributed to an irritation of existing norms and to a substantial, if partial, reorientation of the global legal order. 


\section{Fragmentation and friction}

Regime complexity and legal multiplicity have by now been accepted as conditions of the contemporary global order. In many, perhaps most, issue areas of global governance, different norms and institutions come with overlapping claims to compliance on the part of their addressees, and there is no obvious resolution - legal or otherwise - of the tension between those claims.

While this diagnosis is widely shared and many studies have tackled the origins of complexity and fragmentation (Raustiala and Victor 2004; Abbott, Green, and Keohane 2016), the consequences of the phenomenon are less well understood. When it comes to the outcome of conflicts between competing norms, analyses diverge significantly - some accounts highlight the role of powerful actors, others the influence of dispute settlement institutions, yet others the openings created for weaker states (Alter and Raustiala 2018, 340-43; Wisken 2018). Less well understood are the systemic consequences of complexity. Most assumptions here circle around the destabilizing effects (Gómez-Mera 2016: 569-70). When actors cannot resort to a jointly accepted norm to settle their disputes and are instead free to pursue diverging paths with reference to norms in their favor, prolonged conflict is seen to become more likely. In this image, the irresolution of norm conflicts also undermines the stabilizing force of legal norms and the potential transformation of the global order through constitutionalization. If compliance depends as is widely thought - on the precision of the respective norm, it is bound to be negatively affected if norms compete and call each other into question. Actors may then shift from a norm-oriented to an interest-oriented stance, and the international rule of law stands to suffer from such fragmentation as a consequence (Drezner 2013; Peters 2017: 678-80).

The primary focus in such analyses is on states' cross-institutional strategies to evade existing international obligations (Alter and Meunier 2009: 15-17, 20; Gómez-Mera 2016). Complexity, and norm collisions in particular, opens up a variety of tools to governments to legitimize deviation from commitments in one context by reference to another. States can exploit the strategic inconsistencies so created, and they can forum shop between different institutions (Raustiala and Victor 2004: 299-302). They can also engage in broader "regime shifting" by moving an issue into a different context, or even by creating new treaty regimes and institutions in order to counter existing ones (Helfer 2004; Morse and Keohane 2014).

One central element in this analysis is the legal irresolution of norm collisions. This irresolution is not inevitable - norm collisions in law are ubiquitous but, for the most part, they tend to be innocuous. Legal orders provide conflict norms that determine which of two colliding norms takes precedence - often through hierarchies or later-in-time or lex specialis rules. They also often provide institutional mechanisms - typically courts - to decide instances that remain unclear.

In the global context, however, we only find rudimentary analogues to such structures. International courts have limited jurisdiction and are typically confined to the interpretation of particular instruments, unable to speak authoritatively on conflicts between norms from different origins (Kingsbury 2011). The World Trade Organization 
(WTO) Appellate Body, for example, approaches norm collisions from the vantage point of world trade law, and other norms play a lesser role in its proceedings. Even the International Court of Justice is often limited to the interpretation of particular treaties. It only enjoys general jurisdiction - spanning different parts of international law - where the states involved have explicitly consented to it doing so. Most instances of interface conflicts thus cannot be authoritatively resolved by an international court.

The global legal order also has few equivalents to the conflict norms available in domestic systems. International law has established certain internal hierarchies (such as the concept of ius cogens and Article 103 of the Charter of the United Nations (UN)) and it knows the lex posterior and lex specialis norms typical of national legal orders. The International Law Commission has emphasized these in its attempt at dealing with the phenomenon of fragmentation in international law (International Law Commission 2006) and they may constitute the kernel of a common language across regimes (Birkenkötter, this issue). Yet these norms are of limited applicability in many practical cases of interface conflicts - mainly because the colliding norms tend to be enshrined in instruments with different sets of parties, which in the consent-based order of international law makes it difficult to use one instrument to interpret the other (Pulkowski 2014: 287-93). Furthermore, international law's conflict norms apply only to formal international law, whereas many important collisions involve international and domestic norms, as well as informal norms of various kinds. As a matter of law, therefore, many interface conflicts do not have a straightforward solution.

The practical effects of such irresolution may be mitigated by a shift to new tools of interpretation - tools that focus on 'communicative compatibility' rather than consistent interpretation (Pulkowski 2014), or that provide bridging mechanisms on the part of dispute settlers (Delmas-Marty 2009; Young 2012; Andenas and Bjorge 2015; Peters 2017). These do indeed reduce the potential for friction in individual cases as they eschew hard choices in favor of one or the other of two colliding norms. However, especially with minimalist solutions or pragmatic attempts at avoiding principled stances, the reduced friction in one case may generate greater instability later on, as actors do not find guidance as to future behavior and continued contestation may ensue.

\section{Dynamics of Contestation}

The typical image of interface conflicts and their consequences is that of a snapshot: a dispute between two or more actors at a given moment in time, with diverging norms being invoked and competing institutions involved. In this snapshot, the lack of settlement is pronounced - no clear answer can usually be given as to what the governing norm is, the institutions will have diverging positions, and the risk of friction so widely emphasized in the literature appears real.

Yet interface conflicts do not occur as snapshots. They emerge, prosper and sometimes fade over a considerable period of time, and the moments in which actors are in the dark over the norms they need to comply with may well be relatively short. 
Irresolution may persist as a matter of formal law, but background understandings often shift and consolidate in such a way as to provide guidance on the respective weight of the competing norms. Phases of friction may then be contingent episodes which bring out the contestatory potential of norm collisions but will often give way to a more settled construction of norm relations.

During such phases of friction, actors use different tools to respond to the interface conflict. Some will seek to claim primacy of one norm over the other and try to gain support for such claims. Others may make interpretive moves towards finding common ground or engage in efforts at active coordination and the creation of linkages (Stone Sweet 2012; Faude 2015; Green and Auld 2017; Megiddo 2019). Many of these moves, and the reactions they trigger, have feedback effects, and the norms themselves as well as their relation with one another may look very different at the outset than at a later stage of an interface conflict.

The dynamism of interface conflicts comes into sharper relief when observed from a historical distance. Consider the process through which the fight against the slave trade became established as an exception to the principle of flag state consent on the high seas (Grewe 2000: 554-69; Kern 2004). When the slave trade was abolished in several countries around the turn of the $19^{\text {th }}$ century, the customary principle of flag state consent turned out to be a major obstacle for effective enforcement. Especially Great Britain, which had outlawed the trade in 1807, sought to change the rules of 'visitation' of other countries' ships with a view to policing the prohibition (Kern 2004: 239-40). But it ran into difficulties when trying to reach a broader, multilateral agreement on such change. In response, it began a strategy of 'regime-shifting' by turning to multilateral and bilateral agreements containing (formally reciprocal) visitation rights, eventually concluding agreements with twenty countries. This strategy was also designed to challenge the restrictive customary rules to justify searches of ships flying the flag of non-participating countries, in particular the United States. For long, however, this goal remained elusive still in 1856, Britain had to admit that, in its relation with the US, "we have no legal claim to the right to visit" (Kern 2004: 256). It was only with the onset of the civil war that the US gave up its resistance, clearing the way for the slave trade to be recognized as another exception to the customary flag state principle.

The norm collision between the customary rule and new norms contained in bi- and multilateral treaties unfolded over half a century, and during that time, it left the state of international law unsettled. It created space for British attempts to police the slave trade and bring other countries to accept the right to do so, but it also led to uncertainty and a range of new disputes and incidents. Yet with the benefit of hindsight, this episode also appears as one of contestation and change, eventually leading to the adaptation of international law to a changed moral landscape. The creation of colliding norms helped to shape an environment in which it was ever more difficult to uphold the original rule as a matter of law.

This more dynamic, interactive picture is very different from that typically painted of regime complexity, in which actors forum-shop between different, fixed bodies of norms and rival institutions. Where the latter suggests friction and opportunistic moves to 
strengthen opposed positions, the former highlights the potential for adaptation, convergence and stabilization over time, and it lets interface conflicts appear as elements of the contestatory processes that unfold in the international order at all times (Wiener 2018; Zürn 2018; see also Gholiagha, Holzscheiter and Liese , this issue). The two elements may be two sides of the same coin, but looking at the dynamic, longer-term process helps us to see not only the unresolved character of individual interface conflicts, but also the effects of actors' attempts at positioning themselves towards them. These attempts reshape the normative structure in which they operate, potentially leading to the acceptance of a new relation of the norms at issue.

The dynamic perspective also highlights the fact that interface conflicts are part of a broader, and continuously changing, social context which assigns the competing norms differential weights. The development of an interface conflict over time will frequently be intertwined with a process of social change (see also Gholiagha, Holzscheiter and Liese, this issue; Geis and Wiuff Moe, this issue): as in the slave trade example, the creation and invocation of new legal rules and interpretations is often fueled by changing social norms, and the legal rules feed back into the social process.

Attention to this context of social change helps us to better situate the destabilizing effects of the legal uncertainty that comes with an interface conflict. Where a norm is already subject to societal contestation, the invocation of a competing norm does not so much create uncertainty as express it - it may appear as merely a new, and potent, means of giving voice to such contestation in legal form, facilitated by existing legal multiplicity. Furthermore, where societal contestation gains strength over time, recourse to a competing norm may be a means for the legal system to adjust to the new environment and track social change. In an otherwise rigid international legal order, with high hurdles for formal change, interface conflicts can provide an opening for responding to changing circumstances (see also Krisch 2010: 240). They can enhance the disputation over the meaning and application of rules that is a main driver of change in international law (Sandholtz and Stiles 2009). Seen from this perspective, interface conflicts may also help to avoid the instability that would derive from a gap between formal norms and social values, and provide a path towards an order in which the two are (more) in sync.

\section{Varied Pursuits: Rivalry, Irritation, Navigation}

The snapshot picture of interface conflicts also generates a particularly friction-prone image of actors and their orientations - an image of rivalrous institutions, competing with one another for the predominance of 'their' respective norms; and of norm addressees and implementers faced with the binary choice between either the one or the other.

This is perhaps most starkly on display in the legal sphere. Legal conflict rules have a binary structure as they determine which one of two competing norms applies; actors in the legal system are thus typically portrayed as having to choose one norm over the other. The resulting either/or orientation is exacerbated in the literature on legal fragmentation by the widespread focus on the risk of different courts coming to diverging conclusions. In 
the snapshot of such conflicts, opposing positions of actors appear legally irreconcilable and bound to cause friction unless a hierarchically superior arbiter can be found (Cohen 2018: 315-24). For political scientists, too, the most emblematic (and most widelystudied) cases of interface conflicts are those that pitch rivalrous institutions against one another. These institutions struggle for centrality, and other actors are seen to engage in forum-shopping or regime-shifting between institutions depending on their own interests and predilections. The attempt by developed countries to move intellectual property lawmaking from WIPO to the WTO with the Uruguay Round is a central example here (Helfer 2004; Morse and Keohane 2014). In this image, as in the legal one, contests often appear as zero-sum, either/or affairs in which the institutions involved have much at stake, with little room for compromise and the need for third actors to make a choice. We may observe efforts at conflict management (Kreuder-Sonnen and Zürn, Introduction to this Special Issue), but there will also be cases in which institutional rivalry persists until a winner emerges (see also Orsini, Morin, and Young 2013: 33-35).

Yet legal or institutional rivalry of this kind is often not the only, and perhaps not even the primary orientation of actors involved in interface conflicts, especially if we take into view their longer-term goals. Many such conflicts are triggered not so much to rival but rather to irritate - actors create or refer to competing norms in order to effect a change over time in the understanding of an established norm. An example is the adoption of the Cartagena Protocol on Biosafety in the institutional context of the Biodiversity Convention. The Protocol was not meant to replace the WTO (specifically the SPS Agreement on Sanitary and Phytosanitary Measures) as the major forum for the regulation of trade in goods with genetically modified organisms, but was instead aimed at recalibrating the interpretation of SPS norms in the direction of a more precautionary approach (Pollack and Shaffer 2009: 152-58). The Protocol's position alongside WTO rules is expressed, for example, in the ambiguous formulation of the preamble which recognizes other agreements but also seeks to ensure that the Protocol is not subordinated to them (Safrin 2002). Contrary to the imagery of 'contested multilateralism' (Morse and Keohane 2014), the actors driving the Cartagena Protocol did not seek to create an alternative venue but to irritate existing world trade law and shift it into the direction they favored.

Attention to this irritative dimension leads to a more nuanced appreciation of the degree of friction an interface conflict is likely to engender. While rivalry (especially institutional competition) often forces binary choices and radical shifts, efforts at irritation can usually be met by gradual adjustments that reflect compromise or an approximation of the respective norms over time. The irritative dimension can also be seen as a form of 'applicatory' contestation which does not challenge the authority of an existing norm as such, but merely calls into question the way in which it is applied. Unlike 'validity contestation', such 'applicatory contestation' may often strengthen rather than diminish the contested norm as it can help to revitalize it and generate broader societal legitimacy (see also Deitelhoff and Zimmermann 2018).

While actors pursuing rivalry or irritation are clearly committed to one or the other of the competing norms, this is not necessarily the case for other actors - dispute settlers, addressees, observers. Formal rules of legal interpretation may suggest the need for 
binary choices, but we can observe a much wider range of creative efforts at navigating between the competing norms on the part of actors who avoid taking clear sides in a contest. For judicial bodies searching for common ground, these efforts may involve a turn towards bridging mechanisms, such as ways of taking different norms 'into account' or interpreting them in consistency with one another (Krisch 2010: 285-96; Peters 2017). Observed diachronically, the use of such tools often appears as part of judicial dialogues geared towards a greater approximation over time (Tzanakopoulos 2012), and the 'common language of international law' may help to smooth interactions (Birkenkötter, this issue). Non-judicial actors have yet greater leeway, and they may pursue the search for political compromise, find ways to portray norms as being in sync even if the portrayal is stretched, or give a nod to both sides when defining their own stance (see also Megiddo 2019: 127-31). States and other norm addressees are likely to pursue such conciliatory paths if openly repudiating one of the norms (and the institution associated with it) is costly. For example, many courts and government actors faced with conflict between UN Security Council sanctions and European human rights law have sought to downplay the tension and find ways around it (Krisch 2010: 153-187).

In many interface conflicts, institutional rivalry, efforts at irritation and navigating attitudes will coexist, often with different emphases. Some conflicts are likely to be dominated by one, some by the other actor orientation. Taking all of them - and their consequences over time - into view is central for a full account of the destabilizing effects of interface conflicts. Where institutional rivalry is central, we will expect a comparatively high degree of friction as irreconcilable positions and the need for binary choices limit the prospects of conflict management. But where irritative efforts or navigating attitudes prevail, expectations may be less grim - even if actors seem far apart when seen in a snapshot picture, their strategies over time are less likely to cause major friction.

\section{Interface conflicts over time: two vignettes}

The payoff of the dual broadening of perspective we have suggested above - temporally as well as with respect to actor orientations - should become clearer in the study of actual cases of interface conflicts. In the following, we explore two prominent cases at the intersection of global economic governance and human rights in order to probe the plausibility of the conjectures laid out above. We have chosen this constellation because it generates relatively 'hard cases' - cases which would typically be expected to generate significant friction because they involve two spheres of authority with diverging rationales and institutional contexts (Kreuder-Sonnen and Zürn, Introduction to this Special Issue). Economic governance and human rights are particularly prone to conflict as they reproduce important tensions in the struggle over the direction of global capitalism (but see Moyn 2018). Yet we expect that the image of instability generated by interface conflicts at the intersection of these fields changes considerably if we shift from a snapshot account and a focus on rival institutions to an appreciation of the unfolding of the conflicts as they are construed over time by actors with a potentially broader range of orientations. 


\section{Human rights in World Bank policies}

The World Bank's launch, in October 2018, of its new Environmental and Social Framework (ESF) brought to the fore an interface conflict that has characterized the relationship between the Bank and human rights for four decades (Heupel 2017). The ESF is a new set of environmental and social policies which will progressively replace the older Safeguard Policies. While the Bank claims it will help manage environmental and social risks of projects, the human rights community has been far more skeptical - UN human rights experts have publically criticized the ESF for its lack of 'any meaningful references to human rights and international human rights law, except for passing references in the Vision statement and Environmental and Social Standard' (OHCHR 2014). The Bank, however, insisted that a 'human rights-based approach is outside the scope of the ESF' (World Bank 2018: 47) and kept human rights references to a minimum.

Seen as a snapshot, the two institutional settings - the World Bank and the UN human rights system - seem at loggerheads, and quite irreconcilably, with conflicting positions on which norms should take precedence. Yet these competing positions are embedded in a long struggle over the relation between the Bank's regulatory institutions and human rights, driven by interactions between Bank lawyers, states, international institutions and civil society actors engaged in struggles for social and environmental justice in the many sites affected by Bank-financed projects (Fox and Brown 1998). Early manifestations of this tension began in the 1970s and early 1980s when environmental and indigenous issues gained traction within the Bank. The struggle of indigenous peoples against land dispossession around the Polonoroeste project in the Brazilian Amazon triggered various iterations of a rule-making process for projects with an impact on indigenous groups (Kingsbury 1999; Eastwood 2011). Importantly, those policies drew inspiration, but also distanced themselves, from international standards existing at the time.

From the 1980s to the 1990s, civil society actors construed a second wave of irritations through the invocation of Bank policies and international human rights norms against controversial Bank-funded projects. Much of it was fueled by protests of local and transnational non-governmental organizations (NGOs) against the Sardar Sarovar dam project in India. These protests, jointly with pressure by the US Congress, led to the Morse report, an independent investigation commissioned by the Bank. The report gave an account of the flaws in the Narmada case that meshed together Bank policies and human rights norms, and thus provided a push for greater engagement (Morse and Berger 1992). However, a follow-up internal review a year later failed to refer to any of the human rights norms mentioned in the Morse report (Wyss 1993).

Still, this episode of contestation did lead to significant institutional innovation, in particular the establishment of the World Bank Inspection Panel (Bradlow 1993). In spite of significant resistance on the part of the Bank as well as of some borrowing states, the Panel soon became a potent tool in the hands of social movements. Yet NGOs also criticized the Panel process, targeting especially the limited scope of its mandate which formally excludes jurisdiction over human rights violations. While this exclusion remains in place today, after different rounds of reforms, the Panel has found subtle ways to 
construe an engagement between Bank policies and human rights (Vita, Tan, and Panjshiri 2017). Its counterpart at the Bank's private sector arms, the Compliance Advisor Ombudsman (CAO), focuses on mediation rather than formal decisions and is often perceived to enjoy greater flexibility for the indirect promotion of human rights (Saper 2012: 1300).

This trajectory reflects the winding process through which the World Bank has managed the tension between its own rules and international human rights norms more generally (Sarfaty 2012). Traditionally, the scope of that relationship was seen to be legally constrained by the 'political prohibition' rule in the Articles of Agreement which provides that 'the Bank and its officers shall not interfere in the political affairs of any member'. While human rights advocates tend to invoke the general applicability of human rights norms to international organizations, the World Bank has long regarded the Articles of Agreement, and especially the political prohibition rule, as lex specialis (Genugten 2015). However, through creative interpretation, some lawyers at the Bank have opened up space for a greater weight of human rights norms, with one General Counsel going as far as to state that 'the Articles of Agreement permit, and in some cases require the Bank to recognize the human rights dimensions of its development policies and activities' (Dañino 2006). More recent interpretations have returned to somewhat more cautious positions (Palacio 2006; Leroy 2012). The incorporation of certain, selected human rights norms - for example, indigenous rights or gender equality norms - into the Bank's internal policies took place in the shadow of this broader constitutional question.

The struggle over the relationship between World Bank rules and human rights is ongoing, with positions of the Bank and human rights advocates still far apart. Yet between the 1970s and today, the relative weights of, and distance between, the two bodies of norms have shifted, and the Bank has, albeit cautiously and selectively, come to take human rights concerns into account in a way that would have been unlikely in the past. In part, this came as a strategic response to legitimacy challenges; in part, it stemmed from what appears as an attempt at navigating between competing rules, especially on the part of institutions such as the Inspection Panel which, though institutionally committed, also need to demonstrate their independence.

If human rights critiques continue today, they express ongoing political contestation over the nature of development projects. Yet the resulting picture has little to do with the frequent assumption of destabilization brought about by an interface conflict. It is rather a picture in which an interface conflict, generated by activists with a view to irritating World Bank rules, contributes to a process of incremental change in an institution that remains stable (and has traditionally been relatively immune to challenges from the outside).

\section{Corporate social responsibility and international human rights law}

Globalization has given rise to multinational corporations (MNCs) and transnational corporate networks with global reach, the individual components of which are typically incorporated separately into different national jurisdictions. Since the 1970s, efforts at closing the protection gaps arising from this legal fragmentation have spurred norm 
production in many sites, public and private, and they have engendered competing approaches, expressed in part in colliding norms (Zerk 2006). In the early stages, human rights were largely a marginal concern. The push for a code of conduct for transnational corporations was motivated, on the part of developing countries, by a concern about the intrusive nature of MNCs as agents of 'neo-imperialism'. The focus was thus primarily on the reassertion of government control and development objectives, while developed countries - typically MNC's home states - sought to achieve protections for the companies' investments. This focus is reflected in the (eventually unsuccessful) UN negotiations on a Code of Conduct for Transnational Corporations as well as in the 1976 OECD Guidelines on Multinational Enterprises and also dominates the 1977 ILO Tripartite Declaration of Principles concerning Multinational Enterprises and Social Policy (Sauvant 2015).

The human rights discourse about multinationals stands in tension with this approach, in that it focuses on the avoidance of specific harm and ensuring accountability as opposed to the focus on voluntary, responsible behavior in the CSR discourse. Since the 1980s, concerns about MNCs were increasingly framed in human rights language, driven largely by civil society organizations which responded to well-publicized cases of corporate wrongdoing, social and environmental harm and egregious human rights abuses (Ramasastry 2015).

For long, the impact of this discursive shift - which was in large part aimed at the irritation of existing CSR norms - was limited. The OECD Guidelines incorporated a (very cautious) human rights clause only in 2000. At the same time, significant differences emerged in the human rights camp between proponents of a (non-binding) responsibility of corporations to uphold human rights and those of a (binding) obligation to do so. This divide reflects positional differences about the scope and applicability of human rights law to corporations and, more specifically, the question of whether corporations (should) have direct human rights obligations under international law or whether only states (should) carry such obligations (Zerk 2006: 7-8). The difference became visible in the contrast between the 2000 UN Global Compact, which expresses a voluntary, non-binding commitment in rather soft ('should') language, and the 2003 Norms on the Responsibilities of Transnational Corporations and Other Business Enterprises with Regard to Human Rights, which speak of corporations' 'obligation' to respect human rights and formulate specific prescriptions in much stronger ('shall') form (Weissbrodt and Kruger 2003).

While the 2003 Norms never made it beyond the sub-committee in which they were drafted, the Global Compact enjoyed greater attention, but its human rights language was not seen as sufficient to reorient the landscape of corporate social responsibility, with its myriad of company- and industry-specific codes. The UN - and especially its representative, John Ruggie - thus sought a firmer bridge between the different camps and initiated a stronger push on business and human rights from which emerged, first, the 2008 Protect, Respect and Remedy Framework, and then the 2011 UN Guiding Principles (UNGPs), both endorsed by the UN Human Rights Council (Backer 2016; Bernaz 2016). The UNGPs have since been referenced and incorporated in a wide range of CSR documents, most notably the OECD Guidelines, which added a human rights chapter in 
2011, and the ILO Declaration in its 2017 revision, but also in many more specific industry or company codes.

The emergence of the UNGPs as a central yardstick in the field has not, however, removed contestation. On the one hand, their uptake is still not uniform, and some codes contain merely symbolic references to the UNGPs. On the other hand, there remain challenges from proponents of a harder approach (Wettstein 2015). In 2014, the Human Rights Council voted to establish an intergovernmental working group mandated to 'elaborate an international legally binding instrument to regulate, in international human rights law, the activities of transnational corporations and other business enterprises'. Introduced by Ecuador and South Africa and supported by a civil society coalition and many countries from the developing world, it was strongly opposed by the US and the European Union who favored voluntary commitments. Whatever the outcome of the treaty process, the norm posited by its proponents - hard law obligations under human rights law (with legal ramifications in case of non-fulfilment) - continues to provide a challenge to the softer norm of corporate responsibility to respect human rights as set out in the UNGPs and taken up in many CSR codes (de Schutter 2016). Adding an element of institutional rivalry, proponents of a treaty also posit the UN system as the decisive site for defining the human rights obligations of companies, in contrast to the UNGP approach, which leaves greater space for others.

Even if this challenge persists, the longstanding collision between CSR norms and human rights norms has found a certain consolidation and produced a new normative bottom line on business and human rights. The gravitational force of the UNGPs is such that other bodies of norms are compelled to position themselves in relation to the UNGPs through resolutions, declarations, cross-references, and even incorporation into their respective normative frameworks. The UNGPs occupy a central position in this entangled web of norms, which is illustrative of the way in which normative frameworks operate, are created and enforced in the global arena (Zumbansen 2011). The interface conflict, driven by both irritation and institutional rivalry, is still far from finally settled, but we can see how here (as in the World Bank case) it has been not so much a destabilizing force but a driver of change - an expression of societal contestation which has pushed CSR into a more widely acceptable direction.

\section{Conflict, contestation, and emerging order}

\section{Beyond snapshots}

The interface conflicts in our two cases are not fully resolved - contestation around the place of human rights in World Bank policies is ongoing, and in the CSR case, gaps and challenges remain despite the substantial convergence around the UNGPs. In both cases, actors continue to diverge not only on the interpretation of the primary norms at play, but also on which secondary norms are relevant. Human rights advocates construe human rights norms as generally applicable across the international legal order, creating 
obligations also for international organizations (such as the World Bank) and private actors (such as transnational corporations). These claims clash with invocations of a lex specialis by the World Bank, and with a more limited construction, on the part of those favoring voluntary CSR norms, of international law's relevance in the wider sphere of transnational regulation.

If observed not as a snapshot but over time, however, this continuing irresolution does not seem to lead to chaos or friction of a kind that would call the rule of law into question. Actors have not simply turned from a norm-oriented to an interest-oriented mode of interaction, but have instead pursued norm-based strategies in a decentralized fashion, seeking support from their audiences for their interpretation of the relevant primary and secondary norms (Kreuder-Sonnen and Zürn, Introduction to this Special Issue). This process has led to a gradual reconfiguration of norms that, despite lingering issues of dispute, is widely recognized by societal actors. Human rights have left a mark on the World Bank, even if not altogether officially, without undermining the stability of the Bank's operations or policies. Similarly, in the CSR example, the remaining openness of the linkage between the UN Guiding Principles and other bodies of norms is not such as to heavily destabilize the latter. CSR norms have clearly shifted towards human rights protection as a result of the collision, and even if the precise relationship between both is not altogether resolved, the scope of possible interpretations has narrowed significantly and CSR norms have come to enjoy greater legitimacy as a result of the contestation. In both cases, the proliferation of different codes with similar content has led to a consolidation of a normative core, and a greater alignment with changing social norms increasingly attuned to human rights concerns.

This consolidation was facilitated by the orientations of key actors. Some of them, especially in the business and human rights case, pursued institutional rivalry. But many other actors had different orientations, and those who activated and maintained the conflict were often more interested in irritation than rivalry. In both cases, we could also observe important actors taking a more 'navigational' stance. The World Bank Inspection Panel was a (limited) example in this regard; similarly, some of the National Contact Points under the OECD Guidelines, institutionally somewhat independent, drew on international human rights standards not formally included in the Guidelines (OECD 2009). Moreover, different UN actors managed to navigate between traditional, business-leaning codes and human rights concerns, thereby paving the way towards the Guiding Principles. On the way, other consequential actors not directly committed to one body of norms - from the G8 to business associations - recognized the need for connecting corporate social responsibility and human rights (Ruggie 2007).

\section{A broader picture}

The two cases confirm our initial conjectures to quite some extent, but they can, of course, be no more than a plausibility probe, and they pertain only to one particular constellation, namely the relation of economic governance and human rights. A fuller picture would require a detailed engagement with a much wider range of cases of interface conflicts, 
which is beyond the scope of this article. Yet even a superficial glance at other important instances suggests the broader value of our approach. Perhaps the most emblematic constellation is the "trade and ..." nexus - the relation between WTO rules and norms from other areas, especially health, environment, and human rights (Pauwelyn 2003). This nexus has given rise to many of the initial concerns about destabilization through complexity and fragmentation, for example in the collision between the SPS Agreement and norms granting states greater leeway in the pursuit of environmental and healthrelated goals. Most visibly in the EC-Hormones and EC-Biotech cases, these other norms were invoked to irritate WTO law, to shift its interpretation into a more precautionary direction. These conflicts have provoked significant transatlantic friction and noncompliance, but they have also, over time, led to a certain modus vivendi and rapprochement, expressed in a more cautious language and approach in the WTO Appellate Body as well as altered expectations of states (Lang 2015). Even if the conflict between trade and non-trade rules has not been definitively resolved as a matter of law, a general understanding about the need to find a balance between them has taken hold. Consolidation over time has been yet more pronounced in another prominent "trade and ..." conflict - the conflict between WTO rules on intellectual property and the provision of essential medicines in developing countries. Opponents of the strict approach of the TRIPS Agreement turned to other fora, especially the WHO and the UN human rights system, to generate counter-norms and unsettle the interpretation of WTO rules. Adding to the existing political tension around the topic, the conflict between patent protection and public health goals also became the object of litigation in domestic courts. Yet this friction was relatively short-lived as the contestatory process, and strong civil society mobilization in favor of health concerns, led to a political compromise and the amendment of the TRIPS Agreement (Abbott 2005; Wisken 2018: 275-80). The US pursuit of bilateral treaties with stronger IP protection has challenged this outcome (Drezner 2013) but it has not been able to undermine the new default rule in the WTO context.

We would need to inquire more deeply into these cases to understand the positioning of relevant actors better, and to assess the different degrees of instability they have provoked. Yet we can discern a pattern already encountered in our case studies - a pattern in which interface conflicts appear, in the longue durée, as elements of a process of contestation and adjustment, leading to a certain convergence around a more balanced approach. On our limited empirical basis, we cannot draw firm conclusions as to the various factors that may have facilitated or hindered convergence in these instances; this would require a broader and more systematic study. Yet it is significant that, unlike in many of the paradigmatic and frictitious cases, such as the WTO/WIPO conflict mentioned above, norm conflicts were activated here with primarily an irritative, rather than rivalrous, purpose. This does not ensure an harmonious result, as various of our cases indicate - especially more stable, institutionally committed actors such as the World Bank and the WTO Appellate Body have resisted the consolidation of a more broadly acceptable position. Still, the remaining friction appears as less grave than often thought. More generally, the cases suggest that irritation and contestation leading to gradual convergence over time' is a more common pattern than typically assumed, and perhaps 
more widespread in the dynamics of interface conflicts than the snapshot of institutional rivalry at the heart of the standard account.

\section{Conclusion: Order at the margins}

The global legal order is one of many voices and norms, but this multiplicity does not generally lead to a particular instability or friction. Interface conflicts are commonplace in this order, but in many instances they merely reflect existing societal contestation - the invocation of competing norms gives expression to, and to a certain extent absorbs, legitimacy challenges already raised by states or non-governmental actors. As we have seen, the perception of interface conflicts as destabilizing is often connected to a particular image of rivalrous institutions whereas actors pursuing more irritative aims may often be more open to gradual forms of accommodation. More importantly, irresolution and friction often seem pronounced only when we take a snapshot of an interface conflict. When we observe conflicts over time, we become aware of the tools with which interpreters create relations between different norms that help to reduce uncertainties. And we can perceive how interface conflicts are embedded in broader processes of contestation and social change which, over time, can establish more settled normative expectations about the respective weights of the different norms involved. This may or may not lead to proper legal consolidation - often actors will continue to disagree over the details of competing norms, and also over the secondary norms governing their relationship. Yet this residual contestation should not overshadow the fact that in many instances interface conflicts are not antithetical to order but creative of it - by redefining the margins, the relationships between different bodies of norms, they help to adjust and reconfigure a global order that has few procedures to guide change in more structured ways.

\section{Acknowledgements}

We are grateful to the participants in the OSAIC workshop in February 2019 and in the International Law Colloquium at the Graduate Institute in May 2019 for their feedback and suggestions. We are especially grateful to Christian Kreuder-Sonnen and Michael Zürn for their detailed comments. The research for this article was generously supported by the Swiss National Science Foundation through grant no. 170996 and by the European Research Council (ERC) under the European Union's Horizon 2020 research and innovation programme (grant agreement no. 740634). 


\section{References}

Abbott, Frederick M. 2005. "The WTO Medicines Decision: World Pharmaceutical Trade and the Protection of Public Health." American Journal of International Law 99 (2): 317-358.

Abbott, Kenneth W., Green, Jessica F. and Keohane, Robert O.. 2016. "Organizational Ecology and Institutional Change in Global Governance." International Organization 70 (2): 247-77.

Alter, Karen J. and Meunier, Sophie. 2009. "The Politics of International Regime Complexity." Perspectives on Politics 7 (01): 13-24.

Alter, Karen J. andRaustiala, Kal. 2018. "The Rise of International Regime Complexity." Annual Review of Law and Social Science 14 (1): 329-349.

Andenas, Mads and Bjorge, Eirik. 2015. A Farewell to Fragmentation: Reassertion and Convergence in International Law. Cambridge: Cambridge University Press.

Backer, Larry Catá. 2016. "Governance Polycentrism or Regulated Self-Regulation - Rule Systems for Human Rights Impacts of Economic Activity Where National, Private and International Regimes Collide." In Contested Regime Collisions: Norm Fragmentation in World Society, edited by Blome, Kerstin, Fischer-Lescano, Andreas, Franzki, Hannah, Markard, Nora and Oeter, Stefan , 198-225. Cambridge: Cambridge University Press.

Bernaz, Nadia. 2016. Business and Human Rights: History, Law and Policy - Bridging the Accountability Gap. Routledge.

Birkenkötter, Hannah. (this issue). "International Law as a Common Language Across Spheres of Authority?" Global Constitutionalism.

Bradlow, Daniel D. 1993. "International Organizations and Private Complaints: The Case of the World Bank Inspection Panel." Virginia Journal of International Law 34: 553-613.

Cohen, Harlan Grant. 2018. "Fragmentation." In Concepts for International Law, edited by d'Aspremont, Jean, Singh, Sahib, 315-27. Edward Elgar.

Dañino, Roberto. 2006. "Legal Opinion on Human Rights and the Work of the World Bank." <http://opil.ouplaw.com/view/10.1093/law-oxio/e215.013.1/law-oxio-e215regGroup-1-law-oxio-e215-source.pdf.>

Deitelhoff, Nicole and Zimmermann, Lisbeth. 2018. "Things We Lost in the Fire: How Different Types of Contestation Affect the Robustness of International Norms." International Studies Review (0): 1-26.

Delmas-Marty, Mireille. 2009. Ordering Pluralism: A Conceptual Framework for Understanding the Transnational Legal World. Oxford: HartPublishing.

Drezner, Daniel W. 2013. "The Tragedy of the Global Institutional Commons." In Back to Basics: State Power in a Contemporary World, edited by Finnemore, Martha and Goldstein, Judith, 280-310. New York: Oxford University Press.

Eastwood, Lauren E. 2011. "Resisting Dispossession: Indigenous Peoples, the World Bank and the Contested Terrain of Policy." New Global Studies 5 (1): 1-30.

Faude, Benjamin. 2015. Von Konkurrenz zu Arbeitsteilung: Komplexität und Dynamik im Zusammenspiel internationaler Institutionen. Campus Verlag.

Fox, Jonathan andBrown, David L.. 1998. The Struggle for Accountability: The World Bank, NGOs, and Grassroots Movements. Cambridge, MA.: MIT Press.

Geis, Anna and Wiuff Moe, Louise (this issue). "Normative Turbulences in the Interstices of African and Global Security Governance." Global Constitutionalism.

Genugten, Willem Van. 2015. The World Bank Group, the IMF and Human Rights: A Contextualised Way Forward. Intersentia.

Gholiagha, Sassan, Holzscheiter, Anna and Liese, Andrea. (this issue). "Activating Norm Collisions: Interface Conflicts in International Drug Control." Global Constitutionalism.

Gómez-Mera, Laura. 2016. "Regime Complexity and Global Governance: The Case of Trafficking in Persons." European Journal of International Relations 22 (3): 566-595. 
Green, Jessica F. and Auld, Graeme. 2017. "Unbundling the Regime Complex: The Effects of Private Authority." Transnational Environmental Law 6 (2): 259-284.

Grewe, Wilhelm G. 2000. The Epochs of International Law. Berlin, New York: Walter de Gruyter.

Helfer, Laurence R. 2004. "Regime Shifting: The TRIPS Agreement and New Dynamics of International Intellectual Property Lawmaking." Yale Journal of International Law,29: $1-83$,

Heupel, Monika. 2017. "Human Rights Protection in World Bank Lending: Following the Lead of the US Congress." In Protecting the Individual from International Authority, edited by Heupel, Monica and Zürn Michael, 241-72. Cambridge University Press.

International Law Commission. 2006. "Fragmentation of International Law: Difficulties Arising from the Diversification and Expansion of International Law. Report of the Study Group of the International Law Commission. Finalized by Martti Koskenniemi." A/CN.4/L.682.

Kern, Holger Lutz. 2004. "Strategies of Legal Change: Great Britain, International Law, and the Abolition of the Transatlantic Slave Trade." Journal of the History of International Law 6: 233-258.

Kingsbury, Benedict. 1999. "Operational Policies of International Institutions as Part of the Law-Making Process: The World Bank and Indigenous Peoples." In The Reality of International Law: Essays in Honour of Ian Brownlie, edited by Goodwin-Gill, Guy S., Talmon, Stefan, 323-42. Oxford University Press.

Kingsbury, Benedict. 2011. "International Courts: Uneven Judicialization in Global Order." In Cambridge Companion to International Law, edited by Crawford, James, Koskenniemi, Martti , 203-27. New York: Cambridge University Press.

Kreuder-Sonnen, Christian, and Zürn Michael. (Introduction to this Special Issue). "After Fragmentation. Norm Collisions, Interface Conflicts, and Conflict Management." Global Constitutionalism.

Krisch, Nico. 2010. Beyond Constitutionalism: The Pluralist Structure of Postnational Law. Oxford: Oxford University Press.

Lang, Andrew. 2015. "Twenty Years of the WTO Appellate Body's 'Fragmentation Jurisprudence."' Journal of International Trade Law and Policy 14 (3): 116-125.

Leroy, Anne-Marie. 2012. "Letter to Olivier de Schutter and Cephas Lumina," September 10, 2012. <https://spdb.ohchr.org/hrdb/22nd/THE_WORLD_BANK_09.10.12_(2.2012).pdf.>

Megiddo, Tamar. 2019. “Beyond Fragmentation: On International Law's Integrationist Forces." Yale Journal of International Law 44: 115-148.

Morse, Bradford, and Thomas R. Berger. 1992. "Sardar Sarovar: Report of the Independent Review." International Environmental Law Research Centre. <http://ielrc.org/Content/c9202.pdf.>

Morse, Julia C., and Robert O. Keohane. 2014. "Contested Multilateralism." The Review of International Organizations 9 (4): 385-412.

Moyn, Samuel. 2018. Not Enough: Human Rights in an Unequal World. Cambridge, MA: Harvard University Press.

OECD. 2009. "Final Statement by the National Contact Point for the OECD Guidelines for Multinational Enterprises - Complaint from Survival International against Vedanta Resources Plc."<http://www.oecd.org/investment/mne/43884129.pdf>.

OHCHR. 2014. "Letter from Special Mandate Holders to the World Bank President," December 12, 2014. <https://www.ohchr.org/Documents/Issues/EPoverty/WorldBank.pdf.>

Orsini, Amandine, Jean-Frédéric Morin, and Oran Young. 2013. "Regime Complexes: A Buzz, a Boom, or a Boost for Global Governance?" Global Governance: A Review of Multilateralism and International Organizations 19 (1): 27-39.

Palacio, Ana. 2006. "The Way Forward: Human Rights and the World Bank." Development Outreach, October, 35-37. 
Pauwelyn, Joost. 2003. Conflict of Norms in Public International Law. New York: Cambridge University Press.

Peters, Anne. 2017. "The Refinement of International Law: From Fragmentation to Regime Interaction and Politicization." International Journal of Constitutional Law 15 (3): 671704.

Pollack, Mark A., and Gregory C. Shaffer. 2009. When Cooperation Fails: The International Law and Politics of Genetically Modified Foods. New York: Oxford University Press.

Pulkowski, Dirk. 2014. The Law and Politics of International Regime Conflict. Oxford: Oxford University Press.

Ramasastry, Anita. 2015. "Corporate Social Responsibility Versus Business and Human Rights: Bridging the Gap Between Responsibility and Accountability." Journal of Human Rights 14 (2): 237-259.

Raustiala, Kal, and Victor, David G.. 2004. "The Regime Complex for Plant Genetic Resources." International Organization 58 (1): 277-309.

Ruggie, John Gerard. 2007. "Business and Human Rights: The Evolving International Agenda." The American Journal of International Law 101 (4): 819-840.

Safrin, Sabrina. 2002. "Treaties in Collision? The Biosafety Protocol and the World Trade Organization Agreements." American Journal of International Law 96 (3): 606-628.

Sandholtz, Wayne,Stiles, W. Kendall . 2009. International Norms and Cycles of Change. New York:Oxford University Press.

Saper, Benjamin M. 2012. “The International Finance Corporation's Compliance Advisor/Ombudsman (CAO): An Examination of Accountability and Effectiveness from a Global Administrative Law Perspective." New York University Journal of International Law and Politics 44: 1279-1329.

Sarfaty, Galit. 2012. Values in Translation: Human Rights and the Culture of the World Bank. Stanford: Stanford University Press.

Sauvant, Karl P. 2015. "The Negotiations of the United Nations Code of Conduct on Transnational Corporations: Experience and Lessons Learned." The Journal of World Investment \& Trade 16 (1): 11-87.

Schutter, Olivier de. 2016. "Towards a New Treaty on Business and Human Rights." Business and Human Rights Journal 1 (1): 41-67.

Stone Sweet, Alec. 2012. "A Cosmopolitan Legal Order: Constitutional Pluralism and Rights Adjudication in Europe." Global Constitutionalism 1 (1): 53-90.

Tzanakopoulos, Antonios. 2012. "Judicial Dialogue in Multi-Level Governance: The Impact of the Solange Argument." In The Practice of International and National Courts and the (De-)Fragmentation of International Law, edited by Fauchald, Ole Kristian and NollkaemperAndré , 185-215. Oxford: Hart.

Vita, Viorica, Rachel Tan, and Nealofar Panjshiri. 2017. "The World Bank Inspection Panel and International Human Rights Law." NYU Law School Clinic on International Organizations. <https://www.iilj.org/wp-content/uploads/2017/08/The-WorldBank-Inspection-Panel-FINAL-REPORT.pdf>.

Weissbrodt, David, andKruger, Muria. 2003. "Norms on the Responsibilities of Transnational Corporations and Other Business Enterprises with Regard to Human Rights." American Journal of International Law 97 (4): 901-22.

Wettstein, Florian. 2015. "Normativity, Ethics, and the UN Guiding Principles on Business and Human Rights: A Critical Assessment." Journal of Human Rights 14 (2): 162-182.

Wiener, Antje. 2018. Contestation and Constitution of Norms in Global International Relations. New York: Cambridge University Press.

Wisken, Lea. 2018. Institutional Overlap and Norm Collisions. Doctoral Thesis. FU Berlin.

World Bank. 2018. "High-Level Summary of Comments Received on the Draft ESF Guidance Notes." <http://pubdocs.worldbank.org/en/943801530214217223/ESFBorrower-Guidance-Notes-summary-comment-and-response-matrix-June-2018.pdf. . . 
Wyss, Hans. 1993. "Lessons Learned from Narmada." <http://documents.worldbank.org/curated/en/221941467991015938/pdf/96034BR-PUBLIC-Box391432B-Narmada-Sardar-PUBLIC.pdf $\geq$.

Young, Margaret A. 2012. "Regime Interaction in Creating, Implementing and Enforcing International Law." In Regime Interaction in International Law: Facing Fragmentation, edited by Young, Margaret A., 85-110. Cambridge: Cambridge University Press.

Zerk, Jennifer A. 2006. Multinationals and Corporate Social Responsibility: Limitations and Opportunities in International Law. Cambridge: Cambridge University Press.

Zumbansen, Peer. 2011. "Neither 'Public' nor 'Private', 'National' nor 'International': Transnational Corporate Governance from a Legal Pluralist Perspective." Journal of Law and Society 38 (1): 50-75.

Zürn, Michael. 2018. A Theory of Global Governance: Authority, Legitimacy, and Contestation. Oxford: Oxford University Press. 